\title{
NOTAS SOBRE ANTONIO RIBOT Y FONTSERÉ
}

\author{
Luis F. Díaz LaRios \\ Universitat de Barcelona
}

Antonio Ribot y Fontseré pertenece al grupo de escritores del siglo XIX cuya vida resulta tan interesante como su obra, aunque ni una ni otra hayan merecido atención suficiente. Como sus coetáneos el mallorquín José Andreu Fontcuberta (Andrew Covert-Spring), el catalán Pedro Mata, el castellonense Wenceslao Ayguals de Izco y los valencianos Vicente Boix y José María Bonilla, entre otros, es uno de los románticos levantinos -frecuentemente de filiación progresista- que, en alguna etapa de su vida, se trasladan a Madrid con el bagaje de la reputación adquirida en los círculos literarios de su tierra, para volver a ella tras su estancia en la corte o alternar su actividad en ambas. Tal circunstancia, que coincide en el tiempo con el renacimiento literario contemporáneo en Cataluña, Baleares y Valencia -hago mío el título de Tubino, primer historiador de la Renaixença-, quizá haya sido causa del poco interés que, en general, han despertado estos autores entre los críticos. Para unos, su «espanyolisme» los sitúa en los «orígens del renaixement literari» como meros «precursors»; para otros, quedan relegados a la condición de epígonos de escritores coetáneos por su tardía aparición en la prensa madrileña de la década moderada como periodistas satíricos y traductores al servicio de «La Sociedad Literaria» de Ayguals de Izco o de los editores Gaspar y Roig. Hasta fechas recientes, apenas habían obtenido una referencia al final de un capítulo o una exigua entrada en los diccionarios, repitiendo a veces errores que descubren una sospechosa inercia de respeto a las fuentes.

Tal es el caso de quien me ocupa. En la primera nota biobibliográfica que conozco sobre Antonio Ribot, Ovilo y Otero hace barcelonés a este «excelente poeta» (1859, II: 159-160). Palau y Dulcet (1964, XVI: 479-480), 
le atribuye la novela histórica Don Juan I de Castilla o Las dos coronas y el Examen filosófico penal: Reseña motivada de algunas modificaciones importantes en el código penal vigente que son obras de su hermano José1. También le asigna la autoría de la novela el catálogo informatizado de la Biblioteca Nacional de Madrid² ${ }^{2}$ Es lapsus recurrente desde Cejador (1972, VII: 215), que persiste en dos estudios sobre la novela decimonónica de J. I. Ferreras. En el primero (1976: 94, 163-164 y 172) reitera hasta tres veces la confusión e incluso dedica un breve análisis a Don Juan I de Castilla o Las dos coronas, mientras se limita a citar El quemadero de la Cruz, que sí es de Antonio, «como muestra de la ideología del autor» (165). ¿De José o de Antonio? Hubiera bastado reparar en las portadillas de las dos para subsanar el yerro. Además incluye entre las novelas Solimán y Zaida o El precio de una venganza. Leyenda árabe en verso $(94,163,176)$, que «por su extensión, cerca de las cuatrocientas páginas, más que leyenda es novela» (163), prescindiendo de las observaciones que sobre los «modernos» géneros literarios expone el propio autor en el Prólogo. Más aún: en el breve artículo dedicado a Ribot en el segundo estudio (1979: 346), sitúa El romancero del Conde Duque o la nueva regencia entre «Otras obras novelescas o quizá novelescas» (?), con el comentario sobre esta obrita que desde sus primeros versos toma partido por el «buen duque»: «Se trata de una sátira contra Espartero a la sazón Regente de España» (346a), en coincidencia con Palau («[...] sátira contra Espartero») y el anónimo redactor de la entrada de la Enciclopedia Espasa (51: 358).

Con esa lista de imprecisiones quiero subrayar el poco interés que se ha puesto en comprobar los datos recibidos. Resulta llamativo que apenas se haya sobrepasado la información, generalmente tangencial, sobre este «médico, político y escritor español», como empieza la entrada correspondiente de la Enciclopedia Espasa, o el más detallado principio del Nou Diccionari 62 de la Literatura Catalana (2000: 631a): «crític, poeta, traductor, dramaturg i assagista». La bibliografía específica es, en efecto, escasísima y limitada. De ahí mi interés por acercarme a quien formó parte del «núcleo literario e intelectual de la capital catalana durante la primera parte de la Regencia Cristina» (Juretschke, 1954: 15), que tuvo como

1. Barcelona/Madrid, Luis Tasso, 1858.

2. He consultado el ejemplar de la Biblioteca de Catalunya, cuya portada dice: D. Juan I de Castilla, /o / Las dos coronas. / Novela histórica, original de/ D. José Ribot y Fontseré/ Madrid. / Imprenta de Don José Repullés / Calle del Nuncio, 19, pral. / 1852. El autor llegó a ser catedrático de Derecho de la restaurada Universidad de Barcelona por el tiempo en que lo fueron de sus respectivas disciplinas Bergnes, Milá, Piferrer y Cortada, condiscípulos en Cervera. El Constitucional (24-IV1841) reseña un acto académico en que el «joven profesor [...], catedrático elegido por la Junta», actúa de mantenedor de un debate académico. Colaboró en El Nuevo Vapor. 
órganos de difusión El Vapor (1833-1836), El Propagador de la Libertad (1836-1838) y El Nuevo Vapor (1836-1838).

Quiero dedicar las páginas siguientes al momento de la vida de Ribot que coincide exactamente con dicha etapa histórica, es decir desde que regresa a Barcelona ${ }^{3}$ tras su paso por la Universidad de Cervera ${ }^{4}$ hasta su deportación a la isla de Pinos.

En la capital de La Segarra debió de componer la mayor parte de las Poesías bajo cuyo ropaje de rococó y sentimental convencionalismo disimulaba un trasfondo biográfico. Los sinsabores que habían padecido los Ribot durante el último decenio fernandino quedan aludidos en «La vuelta a mi patria» (70-80), que seguramente guarde relación con la experiencia a la que el autor se referirá años después 5 . Pero tras «el potente cetro /

3. Nació en Vic, en 1813 (Elías de Molins 1895, II: 439) como indican los siguientes versos del autor: « Oh Vich! ¡Oh patria mía!/ esclarecen tu nombre/ salchichones de gusto y de fragancia» («El salchichón», La Risa I, 13: 102b); «iVeinte y tres años!...Joven todavía.../¡veinte y tres años, y la sangre fría / y el alma sin pasión!» («El trovador de Laletania», 1837, del mismo año de su publicación en Mis flores).

En Vic había sido médico prestigioso su padre, don Juan Ribot y Mas, quien se trasladó a Barcelona al ser nombrado catedrático del Real Colegio de Medicina y Cirugía, quizás aprovechando la buena coyuntura política iniciada en 1821 . No parece, sin embargo, que abundaran los días de bonanza en el hogar de este liberal confeso, según recordaría el hijo en «A mi padre en la muerte de mi hermano N.[arciso]» (Poesías escogidas, 1846: 76-80). En los «ominosos años» fue sucesivamente separado y reintegrado a su cátedra, trasladado luego a Cervera y devuelto a Barcelona, quizá poco antes de la muerte de Fernando VII, para ocupar finalmente la primera cátedra de Fisiología en la nueva Facultad de Medicina, de la que llegó a ser decano. Fue miembro de la Real Academia de Medicina y Cirugía al menos desde 1835, en que figura en la Memoria leída en la sesión de apertura de ese año formando parte de la comisión de «Aguas y baños minerales» (cf. $E l$ Vapor, 162, 11-VI-1835). Publicó varios libros sobre las materias que enseñó, alguno de ellos con indudable éxito, como los Elementos sucintos de Fisiología (Barcelona, Estivill, 1822), agotados y ampliados en sucesivas ediciones. Murió en 1851. (Agradezco a la Sra. Lourdes Ciuró, bibliotecaria de la Reial Academia de Medicina de Catalunya, su información bibliográfica).

4. Los años itinerantes de los Ribot son también de formación para Antonio y José, los dos hermanos que han sido confundidos en ocasiones, quizá porque sus vidas discurren paralelas durante algún tiempo. Se sabe de Antonio que estudió en el Colegio Episcopal barcelonés entre 1825 y 1828, y que se encontraba con José en Cervera cuando el padre enseñaba en la universidad borbónica, como documentan los versos de epigonal clasicismo «La visión» $\mathrm{y}$ «A Tisbe», de 1829, recogidos en Poesías (1835: 44-46) y Mis flores (1837: 37-40).

5. Antonio Ribot responde en El Constitucional (31-I-1841) a un artículo del Correo Nacional (23-I-1841) que criticaba la comedia de circunstancias Quiero hacerme bullanguero a la vez que deslizaba insidiosas acusaciones políticas: «[...] No sé quién es el autor del comunicado, pues se encubre cobardemente con el anónimo; aunque tengo suficientes motivos para sospechar que es un exclaustrado, furibundo partidario del tirano Meer y su sistema, y que no hace mucho que elevó a la Regencia una exposición tan mordaz, grosera y atestada de inexactitudes como el artículo a que contesto. Si efectivamente es el autor del comunicado, poco debo resentirme de su crítica majadera, pues entiende todavía menos de literatura que de medicina, a pesar de haber estudiado en Francia, a donde tuvo que partir para romper los vínculos que le unían al altar, y no emigrando por 
que indigno empuña un Monarca» (72), «volverá el siglo de oro a nuestra España» (16). Y una serie de «odas patrióticas», también recogidas en esta primera colección, ponen de relieve sus simpatías por los nuevos protagonistas de la Historia compartidas con otros contemporáneos ${ }^{6}$. Le hacían concebir esperanzas en el futuro la regencia de María Cristina y la amnistía de 1832 («Silva III. La Jura», 12-16; «A la España en el año 1833», 92-93; «Cristina. Canto libre», 105-112), el ministerio de Martínez de la Rosa («Al Excmo. S. D. Francisco [...]», 94-97) y la publicación del Estatuto Real («Himno patriótico. El [...] en el año 1834», 100-102). No pasará mucho tiempo, sin embargo, para que pierda confianza en el nuevo orden y arremeta airado contra quienes reciben sus alabanzas. Y como Larra -con quien se identificó- radicalizará su postura política a medida que vea defraudadas sus expectativas. Pero ahora, de nuevo en Barcelona, parecía que habían terminado las peregrinaciones familiares y la claudicación vergonzosa para salvar la vida de los suyos. Como comentaría en el revelador artículo que acabo de citar en nota:

sus ideas liberales como traidoramente ha dicho a la Regencia [...] Con respecto a lo de «sargento de voluntarios realistas», si toda España estuviese en Barcelona, el «señor D. Antonio Ribot» no tomaría la pluma para contestar a ello. Los patriotas más distinguidos de esta [...] saldrían a mi defensa, porque todos conocen mis ideas constantemente demostradas en los periódicos y en los días de peligro. En aquella época fatal en que el tigre Carlos España hacía consumir en los calabozos o asesinaba en los cadalsos a los ciudadanos más beneméritos, mi padre, catedrático en el colegio de Medicina y Cirugía, fue separado de su destino.

Sufrió con resignación este golpe; pero el absolutismo, insaciable en sus venganzas, le amenazó con otra más terrible. A la sazón visitaba mi padre, como facultativo, a un personaje muy influyente en aquella época por su posición social, quien le dijo confidencialmente que en la Capitanía General obraba contra él una delación atroz, y que para conjurar sus resultados no tenía otro medio que el de hacerme alistar en el batallón de voluntarios realistas. Mi padre, desconsolado, me comunicó la triste alternativa a que se veía reducido [...] Yo era muy niño entonces; contaba apenas catorce años, y me horroricé al considerar que tenía que mancharme con un despreciable uniforme. ¡Huérfano o realista! ¡Y todavía vacilé entre estos dos extremos! Por fin cedí, y no me arrepiento; no tuve bastante temple de alma para resignarme a que el plomo de un soldado arrebatase la vida de aquel a quien debo la mía [...] En buen hora el espíritu de partido acuse de crimen lo que a los ojos del hombre imparcial no es más que un sacrificio. No me arrepiento de mi conducta en aquel trance: salvé a mi padre y a mi familia» (2).

6. He aquí unos sonetos publicados en El Vapor: «Gratitud al trono» (27-IV-1833), «La que naciera a la espumosa orilla»(28-VI-1833), «A par del astro que al ibero augura» (29-VI-1833), de W.[enceslao] A.[yguals] de I.[zco]; «A par del astro bienhechor que brilla», de L. P. (29-VI-1833); «La puerta abriendo al ardoroso estío» (ibíd.), de B.[uenaventura] C.[arlos] A.[ribau]; «El nombre excelso de la gran Princesa» (Ibíd.), de [Pedro] M.[ata]; «A la Reina doña Isabel II» (19-XI-1833), anónimo, como otros que aparecen en los meses siguientes; «A don Francisco Martínez de la Rosa» (25-I- 1834); «Himno con motivo de la solemne proclamación de nuestra Augusta Soberana Doña Isabel II en Alcalá de Henares» (28-I-1834), de Joaquín Pérez Comoto; «Tu nombre, ilustre cándida Princesa» (20-XI-1834), de «un ingenio catalán, residente en la Corte» [¿Aribau?]. 
[...] mientras serví en realistas, ni yo ni mi familia perdimos nuestras relaciones con los patriotas más comprometidos. Por esto, a pesar de haber figurado desde el «Estatuto» en la escena política como periodista y como capitán de nacionales, elegido en los batallones más decididos, nadie, ni moderado ni exaltado, me ha echado en cara lo que fui en aquella época de triste recuerdo».

El todavía estudiante de Medicina ayudaba a su padre en la preparación de un Compendio de las lecciones de Fisiología, dadas en la cátedra por el Doctor Don Juan Ribot, redactadas y publicadas por D. Antonio Ribot (1834) ${ }^{7}$ y sacaba a luz Los descendientes de Laomedonte y la ruina de Tarquino. Este «poema en prosa» es un curioso intento -ya entonces anacrónico- de aunar un asunto inspirado en la tradición clásica -Homero, Virgilio, Ovidio, Tito Livio- con el Numa Pompilio ${ }^{8}$ del «florido» Florian (Peers 1967, I: 196-197 y n. 413), quien también le proporcionó el asunto de su primer ensayo dramático, La independencia de la Suiza (1836).

Sus primeros pasos de poeta son tan vacilantes como los de prosista. Las silvas, odas eróticas, elegías y romances recogidos en Poesías (1835) están escritos bajo la inconfundible sugestión de Meléndez Valdés y los seguidores de su estela, quizá con un grado de evolución cercano al de su amigo Manuel de Cabanyes ${ }^{9}$.

Las tres obras pueden entenderse como el balance de la etapa de formación iniciada en la niñez ${ }^{10}$. Los versos y ensayos que publica desde 1835

7. Es improbable que se hubiera licenciado porque, en tal caso, aparecería su nombre precedido del título correspondiente. No obstante, a la vista de la información contenida en la prensa en que colaboró, se puede asegurar que ya lo había conseguido en 1836, porque en el núm. 1 del Nuevo Vapor (27-X-1836) figura entre los redactores, detrás de Pedro Mata, de quien se dice: «médico, publicista y poeta»; a continuación aparece el nombre de nuestro autor con la indicación «id., id., id.». Y en su citada defensa en El Constitucional contra las insidias del «comunicado» del Correo Nacional, cuyo autor mostraba su despecho, probablemente por haber sido preterido en su aspiración a algún cargo público, Ribot recuerda que durante su deportación en la isla de Pinos, en 1838, ejercía «mi facultad sin remuneración de ninguna especie, me granjeé con mi filantropía y acierto la estimación de aquellos virtuosos colonos». Parece, pues, que puede zanjarse la cuestión sobre las dudas de algunos biógrafos: Antonio Ribot era ya médico en 1836 y como tal actuaba todavía en 1841, año de la publicación de la susodicha respuesta.

8. De 1829 era la edición barcelonesa de la imprenta de Manuel Sauri y Cía.

9. Los parecidos y coincidencias se explican por el mismo ambiente cultural que, en distintos momentos, compartieron en Cervera. La relación personal debió de entablarse más tarde, quizás poco antes de que el poeta de Vilanova y La Geltrú publicara los Preludios de mi lira (Barcelona, impr. de A. Bergnes y Comp., [1833]. Al encargarse Ribot de la sección de poesía de El Nuevo Vapor, anuncia que posee varias composiciones inéditas (5-XII-1836).

10. «Era muy niño todavía, cuando mis dedos hirieron por primera vez el arpa... [...] mis fuerzas eran muy pocas, y las creí suficientes para sobrellevar las dificultades de los géneros más escabrosos. Sin más guía que los estériles conocimientos que me había sugerido el escolasticismo de mis preceptores, mi imaginación desvanecida se perdió entre los descendientes de Laomedonte [...] El 
dejan muy claro el nivel de su filiación liberal frente al conflicto bélico e ideológico entre cristinos y carlistas, político entre moderados y progresistas, y estético entre clásicos y románticos. Todo ello visto desde la óptica del renacimiento cultural que reclama el reconocimiento de la propia identidad catalana, con el que nuestro autor se identifica plenamente. Del «estado de conciencia» de incertidumbre y zozobra que provoca tan complejo marco resulta una literatura «de la experiencia», si se quiere aplicar un marbete que evite el despectivo «de circunstancias».

Desde marzo de 1833 el editor Antonio Bergnes de las Casas publicaba El Vapor dirigido por Ramón López Soler. Entre la información económica y política nacional e internacional de sus páginas queda algún espacio para artículos de costumbres - de Larra, Berenguer Moncada y Lluria (?) -y reseñas, casi siempre sin firma, a veces con seudónimo o una sigla, sobre representaciones de ópera, teatro español antiguo (Lope de Vega, Tirso, Calderón) y moderno (Moratín, Gorostiza, Quintana, Bretón de los Herreros, Martínez de la Rosa, Duque de Rivas, Andrew Covert-Spring, Larra), francés (Molière, Ducis, Arnault, Chénier, Picard, Duval, Hugo, Dumas), alemán (Kotzebue, Schiller) e italiano (Nola). El verso ocupa el segundo lugar: Hojeda, Sinibaldo de Mas, Joaquín Pérez Comoto, Pedro Mata (M. o P. M.), Pedro Martínez López (M. L.), Buenaventura Carlos Aribau (B. C. A.), Wenceslao Ayguals de Izco (W. A. de I.), Bretón de los Herreros, Ventura de la Vega, Corradi, Luis Pons (Marcio), y otros con iniciales de difícil identificación o anónimos. La gran mayoría de las colaboraciones son ilustraciones líricas de las páginas informativas sobre actualidad política y militar y las efemérides de la familia real, de cuya «importante salud» se da parte diario. Todas comparten un patriotismo declaradamente liberal, tan incondicional de la «cándida Princesa» como hostil al «execrable bando».

Este compromiso ideológico se conforma bien con un ideal literario que sin solución de continuidad pasa de «La Primavera» de Mor de Fuentes (8-VIII-1834), «El murciélago alevoso» de fray Tadeo González (11-VIII-1835) y «A Damón que prefiere su cortejo ridículo a su bella esposa» (8-I-1836) a «El mendigo» de Espronceda (16-XI-1835), «El trovador» de Zorrilla (24-III-1836) y «El esclavo de Guinea» de Semís y Mensa (19-I-1836). A la vez recupera y afirma su identidad nacional

respeto y $[\ldots]$ el justo concepto que me había merecido siempre el experimentado literato D. José March y Labores me obligaron a ofrecerle un ejemplar impreso de la obra. [...] Él leyó la composición, la examinó, me manifestó sus defectos [...]. La reacción del desengaño fue poderosa; sin embargo, fue necesario que un primer tomo de poesías y la tragedia (Guillermo Tell) que publiqué después, me repitiesen la lección para enseñarme a no fiar jamás mis obras exclusivamente a mi criterio» (Emancipación literaria, 106-108). 
en «A la Patria. Trobes» (24-VIII-1833) ${ }^{11}$; una canción vertida en prosa poética - ¿por López Soler?- del trovador Guillem de Cabestany (10-VI1834) ${ }^{12}$; La Noya fugitiva (sic) de Tommaso Grossi, traducida al catalán por Juan Cortada (21-VIII-1834) ${ }^{13}$; «Lo vot cumplert» (sic), de Mata con una explicación sobre el espíritu romántico de los versos escritos en catalán (27-VII-1836).

Ciertamente, las dos «escuelas» conviven sin mezclarse ${ }^{14}$, pero a partir de 1835 predomina el romanticismo en El Vapor. A Bergnes y a López Soler sustituyen Rivadeneyra y Pedro Felipe Monlau hasta octubre de 1836 en que Andrew Covert-Spring y una parte de la redacción deciden fundar por su cuenta El Nuevo Vapor.

En ese contexto, en el que subyace un conflicto de intereses económicos e ideológicos, hay que situar a Ribot. «El libre», su primera colaboración en El Vapor (9-VIII-1835), es saludada «con especial complacencia». Unos días después publica «A los catalanes» (30-VIII-1835) y su nombre desaparece del periódico hasta el 26 de julio del año siguiente en que su inseparable amigo Pedro Mata (Fàbregas, 1975: 266-278) lamenta su ausencia en «A A.[ntonio] R.[ibot]». La explicación se encuentra en las «Pa-

11. Editada el mismo año por Bergnes, le precede aquí la nota: [...] escrita para celebrar los días del Sr. D. Gaspar Remisa, es obra de la selecta pluma de D. Buenaventura Carlos Aribau. La presentamos a nuestros lectores con el patriótico orgullo con que presentaría un escocés los versos de sir Walter Scott a los habitantes de su patria».

12. Se adjunta a un comentario sobre el concurso poético propuesto por el Ayuntamiento de Barcelona para celebrar la promulgación del Estatuto Real y la convocatoria a Cortes. Recibirá una medalla de oro como premio el «ingenio que presente la mejor composición poética celebrando la restauración de nuestras leyes a juicio de la Academia de Buenas letras [...] Ello nos transporta a los famosos siglos en que Roger de Flor y Berenguer de Entenza dilataban el nombre catalán hasta las remotas provincias de Oriente [...] Permítasenos presentar en desaliñada prosa una muestra de tales cantos, por si pudiera influir a estimular a los muchos jóvenes dignos de disputarse la honrosa prez del certamen académico».

13. El elogio de la «lengua despreciada por quien desconoce sus encantos en Cabestany y A. March» lleva al reseñista a exclamar: «iAh! ¡Quién sabe si está reservado a la musa lemosina el triunfo de reanimar el antiguo patriotismo y llevarnos de nuevo a desconocidas riberas!». Se trataba, en realidad, de un anuncio de su reciente publicación: La noya fugitiva. Romans escrit en dialecto milanés y en octavas reials per Tomás Grossa, y traduhit en lo mateix metro y en dialecto catalá per Joan Cortada. Barcelona: Estampa de Joaquim Verdaguer, 1834.

14. Andrew Covert-Spring, todavía en Madrid, remite a El Vapor unas «Estrofas al autor de Don Álvaro, o La fuerza del sino» (8-IV-1835) que son un verdadero manifiesto, pues tras elogiar a Rivas por abandonar el estilo de los «rancios», declara: «Yo pretendo cantar al romántico,/ que no en vano soy joven cantor». Por su parte, Milá y Fontanals publica su ajustado artículo «Clásicos y Románticos» (7-VIII-1836) en que sentencia: «No se pretenda [...] crear un monstruoso justo medio: lo clásico como clásico, lo romántico como romántico; cada escuela tiene su fondo, sus bellezas, sus ilusiones, sus formas, su locución, hasta su combinación en los metros y arte en los versos $[\ldots] »$. 
labras del fugitivo», publicadas y enviadas «A su amigo M.[ata]» un mes después:

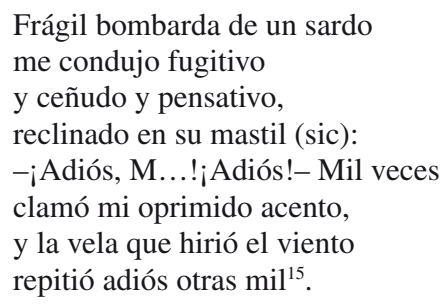

En otras ocasiones aludió también al que parece un precipitado exilio, como en «A mi padre en la muerte de mi hermano N.[arciso]» (Madrid, 1843):

[...] viste a dos de tus hijos fugitivos

a un frágil leño mendigar amparo

$\mathrm{y}$, a merced de aquilones siempre altivos,

golfos retar cual el negrero avaro (79).

Y en el «Prólogo» de las Poesías escogidas que acabo de citar, juzga su Didáctica «[...] obra defectuosísima [...], como no podía dejar de serlo, atendidas las circunstancias en que la compuse, en un país extranjero y careciendo de todo hasta de libros» (pág. VI). Estos textos autobiográficos pueden cruzarse con referencias en la prensa. El Propagador de la Libertad (1836, III, cuaderno 5) resume la sesión del 16 de agosto en que se nombraban los miembros de la «mesa» y los «correspondientes» de la Sociedad Filodramática, entre quienes figura como «literato en París». La estancia en la capital francesa debió de terminar al final del verano porque en octubre se encontraba de nuevo en Barcelona. El Vapor (21-X-1836) adelanta unos «Fragmentos de las Lecciones de poesía que va a publicar Don Antonio Ribot y que [...] leyó en la sesión del 15 de la Sociedad Filodramática». El jueves 27 sale el primer número de El Nuevo Vapor y, aunque consta en la lista de los redactores como encargado de «poesía, prosa, poética», apenas se encuentran colaboraciones suyas en verso ${ }^{16}$. Sí aparece un fragmento de Palabras de fraternidad (27-XI-1836) con la indicación de que continúan las insertas en El Propagador de la Libertad (1836, III, cuaderno 7, 201204). No ha pasado un mes desde su última colaboración firmada cuando

15. El Vapor (24-VIII-1836). «A Mata. Canción del fugitivo», en Mis flores, 113-118.

16. «La emancipación de la mujer» (27-X-1836), «A Isabel, en su cumpleaños» (en colaboración con Milá y Mata) (21-XI-1836). 


\section{El Nuevo Vapor (14-XII-1836) nos sorprende con la siguiente}

Nota de la redacción: Uno de nuestros colaboradores, el joven D. Antonio Ribot, ha cesado desde este día en la parte de redacción que se le había confiado, porque desde este día ha dejado de comprender nuestra marcha en extremo adelantada y progresiva.

Cuesta trabajo aceptar tan abrupta ruptura cuando unos meses antes Andrew Covert-Spring había saludado al «joven poeta» que «[...] realiza en su persona el ideal más brillante de una juventud fuerte y poética, exaltada y tierna, con su candor y energía, su buena fe sincera, sus increíbles ilusiones y sus impetuosos arrebatos» (1836, II, cuaderno 2, 63-64). Pero el distanciamiento ideológico explícito en esa nota hay que considerarlo un caso más del desencuentro producido entre los que se han agrupado hasta ese momento en un proyecto común de romanticismo liberal catalán y el emprendedor sansimoniano (Juretschke 1954: 9-30). Creo que la doctrina expuesta en las obras de las que ofrece adelantos en el diario y revista causa el desvío del jefe de la «escuela armónica». El fragmento de las Lecciones de poesía coincide con el principio de la «Lección última» de la que finalmente llamará Emancipación literaria. Didáctica, influida por el moderado y «divino Ochoa» de El Artista ${ }^{17}$ e impregnada del «romanticismo social» de Saint-Simon (Picard 1947: 231-245) -difundido por Andrew Covert-Spring (Grau 1997: 171-192)- y Lamennais (Canals Vidal 1986², Pageaux 1982), evidente sobre todo en el mesianismo de la lección citada, en la que invita al futuro poeta a escribir una epopeya de «acción grande, nueva y una» (56) cuyo héroe «será un hombre sin mancha, la perfecta/ bella imagen de Dios» (54), e insiste en los «Comentarios» finales:

Sólo aquellas glorias que reflejan con más o menos brillo en el todo de la masa social merecen ser referidas por el sublime cantor, que lleno de entusiasmo convoca al pueblo en aras de la humanidad para que reconquiste sus derechos usurpados por aristocracias parásitas. ¿Reportan tamaño beneficio las proezas de un conquistador? ¿Lo reporta la lanza de un caudillo que cuenta sus víctimas por el número de sus laureles? Solo celebrando la virtud cumple el poeta su misión sagrada, y la virtud es enemiga de sangre, es hija del amor, de este amor sagrado que grabó la mano del Omnipotente en el corazón de los hombres, de este amor que nos recuerda que somos iguales, que somos hermanos, que el mundo entero es

17. Cfr. «Lección V», 27. Ribot transcribe en sus «Comentarios» finales una significativa antología poética que coincide en muchos casos con poesías publicadas por El Artista, según confiesa él mismo (págs. 262-263) y ha confirmado Romero Tobar (1985: 124). El Vapor había anunciado la revista madrileña en enero de 1835. 
una sola familia. No celebremos alucinados al que rompa tan preciosos vínculos; no queramos parecer sus cómplices. La fraternidad universal nos ofrece acciones más sublimes que la gigantesca espada del desesperado Roldán, hendiendo desmesurados peñascos sin perder nada de su divino temple (245-246).

El intento de sintetizar la moderación poética por un lado y por otro la fe en el progreso de la Humanidad con un estilo cambiante, que pasa de la ironía a la exaltación, ha dado lugar a juzgarla, aun reconociéndole el mérito de ser «una de las pocas obras de teoría literaria publicadas en estos años», propia de «un espíritu poco profundo» (Peers, 1967², I: 378 y 382). Sin restar una tilde a la sentencia, hay que recordar, no obstante, que no resulta de una sosegada reflexión sobre preceptiva literaria, sino de una instancia a la emancipación:

mi Didáctica -advierte al «lector preocupado»- es una didáctica que enseña a despreciar todas las didácticas; y yo soy un maestro que te enseño a despreciar (a) los maestros, que te aconsejo no hacer caso de los consejos; en una palabra, que te enseño de no ser enseñado (sic) .

Compuesta en romances heroicos con «comentarios», recuerda la estructura de la Poética de Martínez de la Rosa, a quien cita sólo para establecer distancias. Sus incoherencias y contradicciones son consecuencia del impulso iconoclasta y libertario en el que subyace la creencia en una literatura al servicio de la revolución social. Refleja también la experiencia vital del autor durante su redacción: «proscrito» al empezar a escribirla en el París del progreso y de la plenitud romántica, comprometido a su vuelta a Barcelona con la posición política más radical que acabará provocando su deportación.

Palabras de fraternidad, escritas al mismo tiempo, comparten la ideología que inspira la Emancipación literaria en su dimensión más espiritual, y aclaran el sentido de aspectos confusos o mal integrados. En mi opinión, son obras complementarias. Las 83 páginas de este librito in $16^{\circ}$ constituyen un claro eco de las Paroles d'un Croyant ${ }^{18}$ manifiesto desde el título y continuado en los salmos en que anuncia su evangelio. Pero no únicamente semejan una especie de guía para caminar hacia el nuevo paraíso; son también la propuesta de una nueva literatura: «No consagra hoy la poesía sus mágicos encantos a familias desconocidas, ni revuelve las cenizas de extinguidos imperios para cantar la gloria de héroes que ya no existen» (10).

18. París, Eugène Renduel, 1834. En ese año se tiran al menos ocho ediciones por el mismo editor y se traduce al español en París (Librería de Rosa), Burdeos (Casa de R. Teycheney) y Marsella (Imprenta de Julio Barile y Boulouch). Dos años después publicaba Repullés la versión de Larra: El Dogma de los Hombres Libres. Palabras de un Creyente. 
Con la prosa lírica y solemne de un vidente, Ribot se siente elegido para predicar la nueva religión:

\begin{abstract}
Yo tengo una inspiración grande; una inspiración que me ilumina y desdobla el porvenir para manifestármelo en todos sus puntos: esta inspiración es la idea inmortal del interesante Mata; es el ruido de los pueblos de la Joven Suiza parecido al de la mar que sube; es la palabra de un creyente del virtuoso y venerable LaMennais (Ibíd.).
\end{abstract}

En los «Salmos de esperanza» invita a los «trovadores del nuevo mundo» a cantar la solidaridad, fraternidad, igualdad y libertad que «va(n) a [...] iluminar con su resplandeciente antorcha los caracteres de diamante que ha trazado la mano de Dios sobre tablas de topacio» (28). Pero el «país de los libres» no se logra sin lucha y el «trovador» tañe su laúd para alentar a los esclavos a romper las cadenas; a despreciar a los que esgrimen blasones y riquezas para creerse superiores a los demás hombres y «hacen de la religión un sofisma, de la sociedad una mentira» (46); a compadecer a los proscritos que «han oído las revelaciones del genio de los pueblos y han mirado de hito en hito a los tiranos, sin poder suprimir las convulsiones de su rabia» (50); a derrocar a los déspotas. La conquista de la libertad traerá también la ley acordada e igual para todos porque ambas «van siempre juntas en la tierra como en el cielo la virtud y la bienaventuranza».

En los «Salmos de bienaventuranza» el tono coral se adelgaza y desciende a la intimidad del poeta:

Quiero soñar con un sueño de oro; quiero que mi imaginación sea un jardín, y flores de este jardín mis pensamientos (63-64).

A veces suenan notas de Lamartine en ese sueño:

Oigo una armonía desconocida que recorre a la vez cada una de las fibras de mi corazón... ¡Dios mío!, Tú me has hablado (68).

Aspira a compartir la vida con una compañera que, cuando se marchite la belleza de la juventud, más allá de la pasión, «se amarán (sus) almas [...] con un amor más parecido al del Dios que (los) ha formado» (72). También el amor materno -al que tan sensible fue Ribot- queda anotado en estos salmos, con lo que parece sugerir la doble faceta humana de un sentimiento de origen divino. Si el amor es un anhelo de unión mística, el camino desde la niñez debe recorrerse de modo que, al volver los ojos atrás, no tropiecen con un acto que exija «una expiación». Dichoso aquel que llega a disfrutar 
de una vejez rica, plena y ejemplar como la que desea para sí este «trovador del mundo nuevo». Literatura espiritual, en fin -el autor se presenta siempre como «trovador» $\mathrm{y}$ «misionero»-, al servicio de la revolución social cuya meta es alcanzar una nueva tierra prometida.

¿Podrían interpretarse las poesías de Mis flores y el drama Don Sancho el Independiente como el intento de llevar a la práctica la teoría literaria que Ribot ha formulado, más o menos confusamente, entre 1836 y 1837 ? He de reconocer que sólo en parte, y en un sentido muy lato, satisfacen esa expectativa ${ }^{19}$. De la lectura de esta segunda entrega poética se deduce que su autor, al no renunciar a algunos de sus iuuenilia, integrándolos con otros más cercanos a su exposición doctrinal pero igualmente limitados a su subjetividad y autocompasión, contradecía la misión social que encomendaba al poeta. Creo que era consciente de ello porque parece justificarse en el prologuillo o «Entrada del jardín»:

«No sé cuál es el mérito de mis elegidas, pero puedo asegurar que bastan para mi recreo. Son los ecos de mi ventura, las rosas de mis espinas, las cartas de mi madre durante mi emigración. Su aroma nunca incensó a los tiranos, ni jamás una de ellas ha formado parte del ramillete que los esclavos presentan a sus señores» (5).

Componen Mis flores trasuntos de vivencias sentimentales y prosaicos y declamatorios versos de circunstancias políticas que abarcan desde su estancia en Cervera, en 1829, hasta el presente. Los autores de las citas que gusta de anteponer a sus textos -Florian, Moratín, Quintana, Martínez de la Rosa, [González] Bravo, Ochoa, Espronceda, Romea, Salas Quiroga, García Gutiérrez, Mata, Milá, Zorrilla- apuntan un horizonte de referencias que confirma la todavía vacilante convivencia entre el clasicismo de «A Tisbe», «La sorpresa», «Corina», «Al Céfiro» y «El árbol caído», y el romanticismo de las canciones «La agonía de amor», «El perdón», las sentidas elegías «La madre del trovador» $\mathrm{y}$ «A la memoria de mi madre», y el patriotismo liberal «Al pueblo. Después de las ocurrencias del 5 de agosto», «Himno guerrero», «A Isabel. Improvisación» e «Isabel y Cristina. Canto apocalíptico» $\mathrm{y}$ «Constitución o muerte». No hay cambios apreciables de estilo entre las Poesías de circunstancias políticas publica-

19. Tampoco, en rigor, los ejemplos de los «Comentarios» responden a esa literatura «utópica» que augure un «mundo nuevo» sino, en todo caso, la crisis del «viejo». Es curioso cómo Ribot, que tantos comentarios prodigó sobre la épica, no se atenga a su propuesta de la Emancipación literaria en dos curiosas aportaciones posteriores a la época que ahora importa: El Romancero del Conde-Duque o La Nueva Regencia y Solimán y Zaida o El precio de una venganza (Díaz Larios 1876: 321-347; 1988, 45-52). En ambas evidencia voluntad renovadora acercando su temática al presente, pero olvida el mesianismo heroico de su ideal de 1837. 
das en 1835 y compuestas entre 1832 y ese año, y las de 1837 . Tienen en común la urgencia de su composición bajo la inmediata impresión de los acontecimientos referidos. A lo más, cabría advertir una paulatina intensificación tonal, acorde quizás con la radicalización política del autor, que es su aspecto más interesante, porque, juzgadas literariamente, «no salvan el escollo de la monotonía prosaica» (Juretschke 1954: 18).

Algunas de esas flores sí parecen corresponder a la voluntad de aunar forma e ideología. Es el caso de las que califica de «fantasía» y de poema o canto «social» o «humanitario», fechados sin excepción en 1836 y con epígrafes que remiten a poetas predilectos y colaboradores de las publicaciones madrileñas Revista española y El Artista y de las barcelonesas citadas. Son los casos de «Los proscritos» (págs. 25-33), a Ochoa; «El castillo feudal» (41-52), a medio camino entre el cuento y la desaparición de los privilegios en el mundo moderno, a [González] Bravo; «A los valientes del ejército que sostienen la causa popular. Fantasía» (52-61), a Milá, con explicación final sobre el origen musical del término «fantasía»; «El retroceso sobre la tumba de Lopecio. Escena fantástica» (91-97), al Mata de «Lo vot complert» (Vall 1997, págs. 387-415); «El bandolero catalán» (121-126), a «El verdugo» de Espronceda; «La cruz del desierto» (145-148), a Romea. También cabría agrupar aquí «A Mata. Canción del fugitivo» (113-118), interesante como testimonio de su exilio francés; $\mathrm{y}$ «Los deportados de enero a las islas Canarias» (127-131), que trasciende la circunstancia política -destierro de algunos redactores de El Propagador de la Libertad- para pergeñar una confusa visión de las víctimas del despotismo como campeones de la Libertad y la Virtud. El sentimentalismo compasivo del lema «iDieu guide le pauvre exilé», extraído de Paroles d'un croyant (cap. XLI), invade todos sus versos.

No es casual que cinco de estas flores - «El alma del poeta», «La madre del trovador», «El trovador al paladín», «Los últimos momentos del poeta» $\mathrm{y}$ «A Larra»-, con citas que sugieren sus fuentes de inspiración (Mata, Salas Quiroga y Zorrilla), giren en torno a la «misión social del poeta», porque su teoría de la literatura le llevaba a planteársela. Me parece especialmente significativo que entre las tres más próximas a la fecha de la edición figure la elegía «A Larra». Para Ribot, Fígaro -cuyos artículos había reproducido El Vapor- personifica el poeta idealista y solitario, incomprendido por todos salvo por los «trovadores» y se identifica con su muerte, que justifica como salida de su «laberinto inextricable»:

¿Piensas que, cual tú, no anhelo arrancar mi amarga vida de este círculo de yelo que la mantiene oprimida? (150). 
Quien así escribía quizá pasaba por momentos de melancolía -estaba reciente la muerte de su madre- y sufría los efectos de la inestabilidad política y social que perturbaban la vida urbana. El año 1837 estaba siendo especialmente intenso: los carlistas cosechaban éxitos en varios frentes, llegando hasta las puertas de Madrid; en Barcelona, a la lucha entre moderados y progresistas se añaden los tumultos callejeros, los enfrentamientos entre milicianos y soldados en enero, en mayo... que el barón de Meer, Capitán General de Cataluña, reprime con el mismo rigor que las incursiones de los facciosos. También fue el año en que las Cortes redactaron el proyecto de Constitución que finalmente sancionó la Regente (8 de junio). Aprovechando la coyuntura, aparece el $1^{\circ}$ de agosto El Constitucional, diario progresista de contenido preferentemente político como subraya la habitual colaboración de Fray Gerundio. Junto a sus comentarios satíricos de actualidad aparecen en el «folletín» algunos artículos de crítica literaria histórica («Ariosto y Tasso», «Literatura española») y reseñas de las sesiones de la Sociedad Filodramática.

En el número del 29 de agosto se da cuenta de la del día 15, en que:

D. Antonio Ribot leyó un drama caballeresco en cinco actos y en verso, de su composición, que tiene por título $D$. Sancho el Independiente. Sería hacer un disfavor al público, que muy pronto ha de verle exornado con el aparato escénico, privarle, con darle de antemano una reseña de su argumento, de la novedad de su bien combinada catástrofe; pero creemos que se nos agradecerá el que le prevengamos a favor del primer ensayo dramático-moderno de un joven catalán ya ventajosamente conocido en otros ramos de literatura $[\ldots]$ (3).

Si fue representado o no en el teatro, no me consta. Desde luego no figura en los anuncios teatrales de la última página del periódico, como hubiera sido lógico de haberse estrenado. Al leerlo, recordamos El trovador. La acción se sitúa en las luchas entre el rey Ramiro y su hermano Ordoño por la sucesión del trono de León. En ese tiempo histórico, el protagonista, caballero y trovador, partidario de aquel, y Adela se aman con la oposición del padre, conde de Osma, de la facción vencedora, que prefiere a Mendoza para su hija. En el conflicto político y de intereses, que interfieren la consumación del amor de la pareja, subyace la extrapolación al presente de la fratricida guerra carlista, la lucha entre la vieja aristocracia de sangre y la nueva, que tiene por blasones el valor y la virtud. Nada nuevo ya cuando se escribió. En la nota que acabo de citar se valoraba de este «primer ensayo dramático-moderno» «la facilísima versificación que despliega en todos los actos».

En las páginas de esta primera época de El Constitucional, una sola poesía firma A. Ribot. Junto a otras en que domina el sentimiento amo- 
roso de Pastor Díaz - con la excepción de Ayguals de Izco-, Bermúdez de Castro, G.[ómez] de A.[vellaneda], Zorrilla, Arolas, Detrell, Romero Larrañaga, F.C.y S. el Olotín, «El cedro» (17-IX-1837) explicita un claro simbolismo histórico que trasciende la mera descripción del árbol plantado en el antiguo convento de Jerusalén, convertido ahora en cuartel de la Milicia Nacional. El cedro centenario es testigo del pasado y del futuro:

\author{
En ti dos épocas miro, \\ en ti miro dos ciudades, \\ miro en ti la eternidad; \\ en ti, al describir su giro, \\ se pararon las edades... \\ Puso un sello cada edad: \\ y entre todas hay un sello \\ que formará tu blasón; \\ árbol, reténlo que es bello: \\ «O Muerte o Constitución» ${ }^{20}$.
}

La revolucionaria disyuntiva final tenía doble sentido: era banderín de enganche de los liberales contra los carlistas, que unos días antes se habían acercado hasta las puertas de Madrid; y era también una advertencia a los moderados que maniobraban para derribar a los progresistas del Gobierno, como ocurrió. Ganaron las elecciones, se disolvió la Milicia... y empezaron las represalias contra los desafectos. El 17 de octubre, El Constitucional avisa a sus suscriptores que el jefe político ha ordenado la suspensión del diario. El poeta miliciano Ribot es víctima de su cada vez más exaltado compromiso con la causa popular en sus poesías patrióticas,

y en calabozo lóbrego me hundieron, me trasladaron a un sollado inmundo y un mar que brama por señor me dieron, cuya boca es un báratro profundo ${ }^{21}$.

Así recordaba en 1843 el principio de su Deportación a la isla de Pinos, en donde permaneció hasta finales de 1838. El presidio y la aventura de su fuga dieron lugar a un curioso viaje que terminó en Barcelona a finales de 1839 o principios de 1840 , después de haber padecido por segunda vez la experiencia del proscrito. Pero ese capítulo de su vida merece atención aparte.

20. Recogida en Poesías patrióticas y de circunstancias (1841: 3-5), y Poesías escogidas (1846: 64-65). 21. «A mi padre en la muerte de mi hermano N. [arciso]», Poesías escogidas, pág. 79. 


\section{BIBLIOGRAFÍA}

\section{i. ObRas CITAdAs de Antonio Ribot y Fontseré:}

1834, Los descendientes de Laomedonte y la ruina de Tarquino. Poema en prosa por D.[...], dedicado a doña María Isabel II, Reina de España. Con licencia. Barcelona: Imprenta de Ignacio Estivill, Calle de la Boria.

1834, Compendio de las lecciones de Fisiología, dadas en la cátedra por el Doctor Don Juan Ribot, redactadas y publicadas por D. [...], Barcelona, Impr. de la Vda. e hijo de Texero.

1835, Poesías de D.[...], Barcelona: en la Librería de José Solá, Calle de la Boquería, [en la Imprenta de José Tauló, calle más baja de San Pedro].

1836, La independencia de Suiza. Tragedia en cinco actos, formada en vista del hermoso poema que bajo el título de Guillermo Tell dio a luz El Caballero Florián, por [...], Barcelona: Librería de José Solá.

1837, Mis flores por A. [...]. Barcelona: Imprenta de A. Gaspar y Compañía, Calle de la Platería.

1837, Don Sancho el Independiente. Drama caballeresco en cinco actos y en verso, por D. [...], Barcelona.

1837, Emancipación literaria. Didáctica, de A. [...]. Barcelona, Imprenta de Oliva, en la Platería.

1837, Palabras de Fraternidad por A. [...] / «Congregavit nos in unum Dei amor»/ Barcelona, Imprenta de de Juan Oliveres, Calle de Escudillers, N. 25.

1839, Mi deportación. Trobas marítimas y americanas por [...]/ («sin hallar una sola simpatía/ y buscándola siempre en vano,/ el proscrito en el suelo americano/ la hiel lleva en su pecho noche y día»)/ Barcelona, Imprenta de Gaspar y $\mathrm{C}^{\mathrm{a}}$.

1841, Quiero hacerme bullanguero. Comedia en un acto y en verso por [...], Barcelona: Imprenta de I. Estivill.

1841, Poesías patrióticas y de circunstancias, de [...] Barcelona, Imprenta de I. Estivill.

1842, El Romancero del Conde-Duque o La Nueva Regencia. Por [...] Barcelona: Librería de Ignacio Oliveres. Calle Ancha núm. ${ }^{\circ} 26$.

1846, Poesías escogidas de [...] Madrid: Imprenta del Tiempo, calle de la Magdalena, 38.

1849, Solimán y Zaida o El precio de una venganza. Leyenda árabe por [...]. Madrid: Librería de Gaspar y Roig, Editores, calle del Príncipe, núm. 4. 
1868, El quemadero de la Cruz, víctimas sacrificadas por el Tribunal de la Inquisición. Novela original de [...], Madrid: Imprenta de Gaspar y Roig, editores, (2 vols.).

\section{GENERAL}

Andreu Fontcuberta, José (Andrew Covert-Spring), «Obras poéticas de Ribot», El Propagador de la Libertad, II, Cuaderno 2º 1836, p. 63-64.

Calbert i Camarasa, Josep M. / Jacinto Corbella i Corbella, Diccionari Biogràfic de Metges Catalans, Barcelona, Fundació Salvador Vives Casajuana/ Universitat de Barcelona, Seminari Pere Mata, III, 1983, pp. 32b-33a.

Canals Vidal, Francisco, Cristianismo y revolución. Los orígenes románticos del cristianismo de izquierdas, Madrid, Speiro, $1986^{2}$.

CEJADOR Y FRAUCA, Julio, (facs.), Historia de la lengua y literatura castellana, Madrid, Gredos, VII, 1972, p. 215.

Coroleu, Joseph, Memòries d'un Menestral de Barcelona. 1792-1864, Barcelona, 1888.

Díaz Larios, Luis F., «El Romancero del Conde-Duque, de Ribot y Fontseré, entre la sátira política y el episodio nacional», en: Anuario de Filología, 2, 1976, pp. 321-347.

- «De la épica a la narrativa romántica: Solimán y Zaida, de Ribot y Fontseré», en: Romanticismo 3-4. La narrativa romantica. Atti del IV Congresso sul Romanticismo spagnolo e hispanoamericano (Bordighera, 9-11 aprile 1987), Genova, 1988, pp. 45-52.

El Segle Romàntic. Actes del Col-loqui sobre Romanticisme (Vilanova i la Geltrú, 2-4 de febrer de 1995), 1997, Vilanova i la Geltrú, Biblioteca Museu Víctor Balaguer.

Elías De Molins, Antonio, Diccionario Biográfico y Bibliográfico de Escritores y Artistas Catalanes del Siglo XIX, Barcelona, Administración, II, 1895, pp. 439-445.

Enciclopedia Universal Ilustrada, Madrid, Espasa-Calpe, 51, p. 358a.

FÀBREGAS, Xavier, Les formes de diversió en la societat catalana romàntica, 1975, pp. 266-278.

FERreras, Juan Ignacio, El triunfo del liberalismo y de la novela histórica (1830-1870), Madrid, Taurus, 1976.

- Catálogo de novelas y novelistas españoles del siglo XIX, Madrid, Cátedra, 1979. 
GHANIME, Albert, «Aproximació als periòdics i als periodistas de la Barcelona de 1820 a 1839», Cercles d'història cultural, 5, 2002, pp. 52-78.

Gran Enciclopedia Catalana, Barcelona, 19, s.v. «Ribot i Fontseré, Antoni», 1975.

Gras y Elías, Francisco, Siluetes de escriptors catalans del sigle XIX, Barcelona, Librería «L'Avenç», 1909, pp. 52-60.

GRAU, Marie, «Romanticisme, estètica saint-simoniana, «escola harmònica». Les idees literàries d'Andrew Covert-Spring», en: El Segle Romàntic, 1992, pp. 171-192.

Jorba I Jorba, Manuel, Manuel Milà i Fontanals en la seva època, Barcelona, Curial, 1984.

— «El Romanticisme», en: M. Riquer/ A. Comas/ J. Molas, Història de la literatura catalana. Part Moderna, Barcelona, Ariel, VII, 1986, pp. 77-122.

— «Els romanticismes de Catalunya», en: El Segle Romàntic, 1997, pp. 209-248.

JuRESTSCHKe, Hans, «Del romanticismo liberal en Cataluña», en: Revista de Literatura, VI, 11-12 (julio-diciembre), 1954, pp. 9-30.

OsSORIO y BERnARD, Manuel, Ensayo de un catálogo de periodistas españoles del siglo XIX, Madrid, Imprenta de José Palacios, 1903, p. 377a.

Ovilo y Otero, Manuel, Manual de biografía y de bibliografía de los escritores españoles del siglo XIX, Paris, Rosa y Bouret, II, 1859, pp. 159-160.

Nou Diccionari 62 de la Literatura Catalana, Barcelona, Edicions 62, 2000, 631a.

Palau y Dulcet, Antonio, Manual del librero hispanoamericano. Inventario bibliográfico de la producción científica y literaria de España y de la América latina, Barcelona, Librería Palau, XVI, 1964², pp. 479-480.

Pageaux, Daniel-Henri, «Lamennais en Peninsule Ibérique: Notes sur la difusión des idées mennaisiennnes en Espagne et au Portugal (1834-1840)», en: Utopie et Socialisme au Portugal au XIX ${ }^{e}$ siècle. (Actes du Colloque, Paris, 10-13 janvier 1979), Paris, Centre Culturel Portugais, 1982, pp. 121-152.

Peers, E. Allison, Historia del movimiento romántico español, Madrid, Gredos, $1967^{2}, 2$ vols.

PICARD, Roger, El romanticismo social, México, Fondo de Cultura Económica 1947.

Romea Castro, Celia, Barcelona romántica y revolucionaria (Una imagen literaria de la ciudad. Década 1833 a 1843), Barcelona, Publicacions de la Universitat, 1994. 
Romero Tobar, Leandro, «La Poética de Braulio Foz en el marco de la preceptiva literaria contemporánea», en: Cuadernos de Estudios Borjanos, 15-16, 1985, pp. 111-129.

Tubino, Francisco M., Historia del renacimiento literario contemporáneo en Cataluña, Baleares y Valencia, Madrid, Imprenta y fundición de M. Tello, 1880.

VALL, Xavier, «Lo vot complet, de Pere Mata, un poema presentat com el pioner del romanticisme literari català», en: El Segle Romàntic, 1997, pp. 387-415.

\section{Diarios y ReVistas CONSUltados}

Constitucional, El [(1ª́poca) 1.VIII-17.X.1837]. Barcelona.

Nuevo Vapor, El [1836-1838]. Barcelona.

Propagador de la Libertad, El [1835-1838], («El que escribe siembra. El que lee recoge».)/ Por unos amigos/ [F. Raull, A. Covert-Spring, J. Gener y Solanes, A. Bohemann, P. Mata, J. Eydonx, A. Gironella, J. Strozzi, F. Altés y Gurena, A. Ribot]/ Tomo primero./ Barcelona / Imprenta de J. Verdaguer./ Con licencia.

Vapor, El [1833-1836], Periódico mercantil, político y literario de Cataluña, publicado bajo los auspicios de S.E. el Capitán General, dedicado al Ministerio de Fomento General del Reino.- Año $1^{\circ}$. Núm. 1/Viernes, 22 de marzo de 1833./ Precio 1 r.vn.// Este periódico sale los martes, viernes y sábados por la mañana [...]// (Infraescrito de la última página: Imprenta de A. Bergnes y Comp.). 